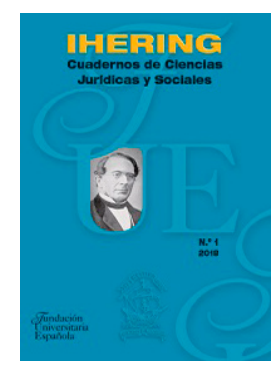

\author{
Ihering. Cuadernos de Ciencias Jurídicas y Sociales \\ $\mathrm{N}^{\mathrm{o}} 1$
}

Año: 2018

e-issn: 2660-552X

DOI: https://doi.org/10.51743/ihering.11

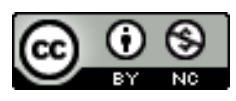

\title{
Constitución española. ¿La reforma pendiente?
}

\author{
JOAQUÍN RUIZ DÍAZ
}

Escuela Internacional de Doctorado. Universidad Rey Juan Carlos

\section{INTRODUCCIÓN.}

廿1 próximo 6 de diciembre se cumplirá el 40 aniversario de la aprobación En referéndum de la vigente Constitución Española.

Los textos constitucionales no son entes inmutables. Aunque, evidentemente, su modificación debe realizarse basándose en criterios objetivos y de verdadera necesidad, puesto que se trata de la norma que corona la pirámide legislativa, y por lo tanto es fuente de los textos con los cuales el legislador dirige la convivencia del país, existen una serie de circunstancias, que pueden ser tanto de carácter interno como externo, que requieren cambios constitucionales.

Evidentemente, estos cambios deben realizarse con todas las garantías a fin de no desvirtuar el espíritu del texto constitucional, manteniendo siempre el objetivo de garantizar la igualdad y los derechos fundamentales de los ciudadanos del estado. Para ello, en el caso del texto constitucional español existen dos procedimientos de modificación - el simple u ordinario y el agravado - cuyos requisitos son diferentes, en función de la importancia de la modificación. ${ }^{1}$

\footnotetext{
${ }^{1}$ El texto constitucional español, define en el Art. 168 las materias a modificar por el procedimiento agravado, siendo estas las que afectan al Título preliminar, al Capítulo II, Sección 1. ${ }^{\text {a }}$, del Título I, o al Título II. El resto de las materias serán modificables por el procedimiento simple u ordinario. El procedimiento agravado, requiere que el proyecto de reforma
} 
Durante este periodo, ha sido modificada en dos ocasiones ${ }^{2}, \mathrm{y}$ ambas han sido realizadas por el procedimiento simple u ordinario. ${ }^{3}$

Esto supone que durante sus 40 años de vigencia no ha sufrido prácticamente modificaciones, en comparación con las de otros países pertenecientes o no a la Unión Europea, lo cual puede por un lado significar que se trata de un texto constituyente muy estable, o muy joven en comparación con las de otros estados, e incluso que las modificaciones a la misma requieren un procedimiento muy exigente. ${ }^{4}$

Lo cierto es que en varias ocasiones se ha debatido sobre la necesidad de realizar diversas modificaciones, e incluso como veremos algunas de ellas figuraban en el programa de gobierno de algún presidente de este, e incluso

sea aprobado por una mayoría de dos tercios en ambas Cámaras, la disolución inmediata de las mismas y la celebración de nuevas elecciones. Las nuevas Cámaras constituidas a continuación, deberán ratificar la decisión y proceder a estudio del nuevo texto constitucional y aprobarlo por mayoría de dos tercios. Una vez aprobada la reforma por las Cámaras, se realizará un referéndum preceptivo vinculante.

El procedimiento ordinario, exige mayoría de tres quintos en las Cámaras, o, en caso de no haber acuerdo, de una comisión paritaria de ambas, que presentaría un texto para su aprobación. De no lograrse la aprobación por este método, siempre que el texto a reformar hubiera obtenido mayoría absoluta en el Senado, el Congreso podrá aprobar la reforma por mayoría de dos tercios. No se precisará referéndum, salvo que lo solicitara en un plazo de quince días, la décima parte de los miembros de cualquiera de las Cámaras sería vinculante.

${ }^{2}$ Nuestra Constitución es rígida, pero sin cláusulas de intangibilidad. Esto quiere decir que su procedimiento de reforma requiere trámites, pero es susceptible de modificaciones en base las condiciones establecidas en la misma.

${ }^{3}$ La primera reforma constitucional (Boletín Oficial del Estado de 28 de agosto de 1992) consistió en añadir, en el artículo 13.2, el inciso "y pasivo" referida al ejercicio del derecho de sufragio de los extranjeros en elecciones municipales.

La segunda (Boletín Oficial del Estado de 27 de septiembre de 2011) consistió en la sustitución íntegra del artículo 135 de la Constitución a fin de garantizar el principio de estabilidad presupuestaria vinculando a todas las Administraciones Publicas, reforzar el compromiso de España con la Unión Europea y garantizar la sostenibilidad económica y social, en el marco de la última crisis económica.

${ }^{4}$ A título de ejemplo, la constitución alemana ha sido modificada en 60 ocasiones desde 1949, la última en 1992, la italiana de 1947 lo ha sido en 15 ocasiones, la francesa de 1958 en 24 ocasiones y la de Portugal de 1976 lo ha sido en 7. Fuera de Europa, la constitución estadounidense, cuyo texto se elaboró en 1787 y fue aprobada en 1791, acumula 27 enmiendas, la última en 1992. 
expertos en diversas ramas del Derecho, magistrados, catedráticos u otros destacados personajes han puesto en evidencia la necesidad de realizar algunas modificaciones concretas.

Igualmente, desde el ámbito de la política distintos actores de esta han planteado en diversas ocasiones diversos cambios, si bien no siempre desde puntos de vista transparentes.

Lo cierto, es que desde 1978 nuestra Constitución ha sufrido muchas y muy importantes modificaciones — mutaciones o cambios no formales según el profesor de Derecho Constitucional de la Universidad del País Vasco, Javier Tajadura Tejada - causadas por las leyes, tratados a los que España está adherida, o sentencias del Tribunal Constitucional. ${ }^{5}$

Por otro lado, durante el tiempo de vigencia de nuestro texto constituyente, la situación de partida de este ha cambiado considerablemente en bastantes aspectos y, en la redacción de la Constitución pudieron quedar puntos no demasiado bien definidos, que con el transcurso del tiempo se han demostrado obsoletos en virtud del cambio político, social y en algunos aspectos económico de nuestro país.

En consecuencia, el presente trabajo tiene como propósito revisar algunos de los cambios que han venido siendo demandados y su necesidad, así como la oportunidad y posibilidades de realización de estos.

\section{LOS ORÍGENES DEL CAMBIO. UN POCO DE HISTORIA.}

Durante el proceso constituyente hubo dos aspectos que fueron cruciales para el buen fin del proyecto constitucional. Estos fueron el diálogo y el consenso.

Tras la celebración de las primeras elecciones democráticas desde febrero de 1936, celebradas el 15 de junio de 1977 y la formación de un nuevo gobierno de consenso amplio - hay que tener en cuenta que ningún partido obtuvo mayoría absoluta - que adquirió tintes de gobierno de centroizquierda, e incluyó democratacristianos como Marcelino Oreja y Landelino Lavi-

${ }^{5}$ Tajadura Tejada, Javier; "Reforma, mutación y destrucción de la Constitución"; Fundación FAES; Cuadernos de Pensamiento Político nº 58; ABRIL/JUNIO 2018; Pág. 6. 
lla, socialdemócratas como Francisco Fernández Ordoñez y Juan Antonio García Diez, liberales como Joaquín Garrigues Walker e Ignacio Camuñas y reformistas del Movimiento como Rodolfo Martín Villa y Enrique Fuentes Quintana, se generó una cierta discusión acerca de si las Cortes surgidas tras las mismas, serían Constituyentes. Ni en el texto de la Ley para la Reforma Política ni en el decreto de convocatoria de las elecciones figuraba explícitamente esta tarea.

Éste argumento fue utilizado principalmente por Alianza Popular para oponerse a su carácter constitucional. Sin embargo, la mayoría de la clase política representó el sentir de la población, y consideró que sí estaban capacitadas, por lo que finalmente incluso los sectores más reacios de Alianza Popular se terminaron por integrar en el proceso de consenso que se llevó a cabo con el fin de que ninguna fuerza política demócrata quedara excluida en el proceso. (Barrera, 2004:909) ${ }^{6}$

Los debates no estuvieron exentos de disparidad de criterios, ya que para Adolfo Suárez quedaba claro que no se podía dejar excluido a nadie que tuviera intenciones de participar en el juego democrático, a pesar de los riesgos que ello implicaba, como la legalización del PCE, con la cual el estamento militar se sintió de alguna manera traicionado y tentado de intervenir otra vez en el proceso democrático para "reconducirlo" nuevamente.

Por ello, la renuncia por parte del citado PCE, así como del PSOE, a sus ideologías más extremistas, supuso un ejercicio de conciliación que propició la participación de todos los partidos representativos en los debates de la ponencia constitucional. La capacidad de negociación y consenso en los debates - aunque no exentos en algún momento de conflictividad $-{ }^{7}$ permi-

\footnotetext{
${ }^{6}$ El autor del texto así lo argumenta en la obra citada. Sin embargo, la Ley para la Reforma Política en su Art. $3^{\circ}$ Uno, textualmente cita:

Uno. La iniciativa de reforma constitucional corresponderá:

a) Al Gobierno

b) Al Congreso de los Diputados.

Sin hacer distinción sobre si se refiere a las Cortes continuistas del periodo franquista o a las surgidas de las elecciones democráticas posteriores. En consecuencia, cabría entender que lo expuesto por el Profesor Barrera es objetivamente la excusa de los sectores más reaccionarios ante la posibilidad de la elaboración de una Constitución democrática.

${ }^{7}$ A título de ejemplo, Gregorio Peces Barba, representante del PSOE, abandonó los debates
} 
tió dar a luz un texto constituyente admitido por todos, poniendo el foco en el resultado final y no en las aspiraciones particulares.

Éste fue el gran triunfo del restablecido sistema democrático en España, que todos los actores participantes entendieran que por encima de sus intereses partidistas había un interés general que era prioritario y de mayor importancia.

En base a ese consenso, el 1 de agosto de 1977 se nombraron siete personas para constituir una ponencia que elaborara el primer texto constitucional. En la composición de la misma había representantes de todos los partidos políticos con representación parlamentaria, los cuales fueron Jordi Solé Tura (Grupo Parlamentario Comunista), Miquel Roca Junyent (Grupo Parlamentario de la Minoría Catalana), José Pedro Pérez-Llorca y Rodrigo (Grupo Parlamentario de Unión de Centro Democrático), Gregorio Peces Barba Martínez (Grupo Parlamentario Socialista), Miguel Herrero Rodríguez de Miñón (Grupo Parlamentario de Unión de Centro Democrático), Manuel Fraga Iribarne (Grupo Parlamentario de Alianza Popular) y Gabriel Cisneros Laborda (Grupo Parlamentario de Unión de Centro Democrático)

El 5 de enero de 1978, se publica en el Boletín Oficial de las Cortes el texto del anteproyecto y los votos particulares de los ponentes, abriéndose un periodo de veinte días naturales para la presentación de enmiendas. La Comisión de Asuntos Constitucionales del Congreso debatió el informe durante 24 sesiones celebradas en los meses de mayo y junio. El Dictamen de la Comisión, las enmiendas que se mantenían para su defensa ante el Pleno y los votos particulares se publicaron en el Boletín Oficial de las Cortes, núm. 121, de 1 de julio de 1978 y fue aprobado el día 21 por el Pleno del Congreso.

En base a lo dispuesto en la Ley para la reforma Política, al existir discrepancias entre los textos aprobados por el Congreso y el Senado, fue necesario constituir una comisión mixta de Diputados y Senadores que llegase a un texto común.

El dictamen de la Comisión Mixta sobre el Proyecto de Constitución fue sometido a votación nominal y pública por cada Cámara, en sendas sesiones plenarias celebradas el 31 de octubre de 1978 y aprobado por ambas.

constitucionales el 7 de marzo de 1978, por desacuerdos de su partido respecto a los Arts. 16 y 28 , aunque finalmente el 10 de abril del mismo año, firmó con todos los ponentes el anteproyecto de la Constitución. 
En el Congreso, de los 345 votos emitidos, 325 fueron a favor, 6 en contra y 14 abstenciones. En el Senado, de 239 asistentes, votaron a favor, 226, en contra, 5 y las abstenciones fueron 8. Los presidentes de ambas Cámaras comunicaron al Presidente de las Cortes los resultados de la votación y éste declaró formalmente aprobado el Dictamen de la Comisión Mixta en el Boletín Oficial de las Cortes núm.177, de 6 de noviembre de $1978 .^{8}$

Los ciudadanos españoles, refrendaron el texto constitucional el 6 de diciembre de ese mismo año, con una mayoría aplastante del $87,87 \%$ de votos a favor.

\section{DEMANDAS DE CAMBIO.}

A lo largo de los 40 años de vida de nuestra Constitución actual, se han producido demandas de modificación de esta en varias ocasiones.

El 14 de marzo de 2004, el PSOE gana de forma inesperada ${ }^{9}$, unas elecciones marcadas y según distintas opiniones, influenciadas por los atentados cometidos por el terrorismo islamista en Madrid. El PSOE obtuvo un $43,27 \%$ de votos y 164 escaños y el PP un $37,81 \%$ de votos y 146 escaños. ${ }^{10}$

El candidato del PSOE, José Luis Rodríguez Zapatero, obtuvo la investidura apoyado por los votos de ERC (8), IU-ICV (5), CC (3), BNG (2) y CHA (1)

José Luis Rodríguez Zapatero, en su discurso de investidura, expone en el marco de su promesa electoral de abordar la renovación de la vida pública, su intención de realizar reformas constitucionales sobre cuatro aspectos concretos.

\footnotetext{
${ }^{8}$ Información obtenida en http://www.congreso.es/consti/constitucion/elaboracion/

${ }^{9}$ La mayoría de las encuestas preelectorales apuntaban a una nueva victoria del PP con mayoría absoluta. Así, el CIS en su estudio 2555 (Enero-Febrero 2004) otorgaba al PP una estimación de voto del $42,2 \%$ y 176 escaños y al PSOE un 35,5\% y 131 escaños. EL PAÍS del 6 de marzo de 2004, otorgaba al PP un $42 \%$ de estimación de voto, con una horquilla de 168-172 escaños y al PSOE un 38\% con una horquilla de escaños de 134-141.

${ }^{10}$ Datos obtenidos de la página web del Congreso de los Diputados cuya fuente es la Junta Electoral Central:

http://www.congreso.es/consti/elecciones/generales/resultados.jsp?fecha=14/03/2004
} 
Fue la primera vez que un candidato a presidente del gobierno de la democracia exponía explícitamente en su debate de investidura, la necesidad de realizar reformas constitucionales, ya que si bien el debate sobre la necesidad de reforma de determinados aspectos, como las funciones del Senado, ya se había apuntado, se mantenía un cierto acuerdo tendente a la estabilidad del texto constitucional.

El primero de ellos se refiere a la reforma del Senado, basándose en "la necesidad de reforzar la cohesión y la vertebración de España y en defender la identidad de las Comunidades" haciendo hincapié en que esta "debe plantearse en un proceso consensuado de reforma parcial de la Constitución". ${ }^{11}$

El resto de reformas apuntadas por el candidato a la investidura, se referían a: la regulación del orden de sucesión a la Corona, a fin de eliminar la discriminación de las mujeres en la línea sucesoria, incluir en el texto constitucional la denominación oficial de las diecisiete Comunidades y las dos Ciudades Autónomas, a fin de destacar la importancia de las mismas como parte esencial del Estado y por último incorporar así mismo una referencia a la futura Constitución Europea, como signo de nuestro compromiso y valor real como ciudadanos europeos. $^{12}$

Para llevar a cabo este proyecto, se solicitaría un informe previo al Consejo de Estado, para lo cual "[...] el Gobierno procederá al nombramiento de un nuevo Presidente del Consejo de Estado, de reconocido prestigio y probada independencia, para que dirija ese trabajo". ${ }^{13}$

Ninguna de estas reformas anunciadas se ha llevado a cabo. El informe elaborado por el Consejo de Estado mostró que la puesta en práctica de todas y cada una de ellas, iba a tener implicaciones más complejas, e incluso interdependencias entre ellas, que las que el candidato a presidente había previsto.

De hecho, las modificaciones a realizar según el Consejo de Estado podrían suponer modificaciones de aproximadamente 60 artículos, un $30 \%$ del texto constitucional, y que como en el caso de la eliminación de la discrimi-

${ }^{11}$ Discurso de investidura de José Luis Rodríguez Zapatero, 15 de abril de 2004, Diario de Sesiones del Congreso de los Diputados, Pág. 18.

${ }^{12}$ Id. Pág. 19, Extracto no literal.

${ }^{13}$ Id. Pág. 19. 
nación de las mujeres en la sucesión a la Corona, exigiría el procedimiento agravado del Art. 168 C.E., siendo precisa, entre otras obligaciones legales, además de las mayorías cualificadas de las Cámaras para su aprobación, la disolución de las mismas y la convocatoria de un referéndum, el cual habría que tratar de que no se convirtiera en un referéndum sobre la forma de la Jefatura del Estado (Monarquía o República), lo que da idea de la transcendencia de las modificaciones.

Estas conclusiones nos darían una idea de las dificultades derivadas de la rigidez de las reformas en nuestro texto constitucional. Conviene, por lo tanto, antes de demandar cambios, calibrar las consecuencias de estas y sus efectos sobre el texto constituyente.

Para Javier Tajadura, los textos constitucionales nacen con el propósito de regir la vida del Estado indefinidamente, pero la realidad política sobre la que despliegan sus efectos está sometida a un constante proceso de cambio, por lo cual no es una norma impermeable al cambio histórico y por lo tanto todas las constituciones experimentan cambios en su sentido, alcance y significado, clasificables según dos criterios — de carácter formal o procedimiento y de carácter sustantivo o alcance material - que marcan el grado de los mismos. ${ }^{14}$

Según el primer criterio los cambios podrían ser de carácter formal, esto es a través de un procedimiento regulado por el propio texto, o informales, también denominados mutaciones constitucionales.

Según el segundo criterio debemos distinguir entre los referidos a aspectos no esenciales, que no afectan a la identidad, pilares y fundamentos básicos de la Constitución, de los esenciales, que si afectan al núcleo constituyente y pueden alterar la identidad de una Constitución. Este segundo criterio marca la distinción entre reforma o destrucción de esta, esto es entre cambios "en" y cambios "de" la Constitución. ${ }^{15}$

En consecuencia, debemos ponderar cuidadosamente la necesidad, la oportunidad y las consecuencias de los cambios que se propongan, exploran-

\footnotetext{
14 Tajadura Tejada, Javier; "Reforma, mutación y destrucción de la Constitución”; Fundación FAES; Cuadernos de Pensamiento Político nº 58; ABRIL/JUNIO 2018; Pág. 5.

${ }^{15}$ Ibid. Pag. 6.
} 
do vías alternativas a los mismos, como las ya mencionadas mutaciones constitucionales.

\section{¿QUE CAMBIAMOS Y CUANDO?}

Desde la propuesta del presidente Zapatero, referida a las reformas a realizar, a lo largo de los años transcurridos hasta la fecha, se han venido realizando por parte de diversos estamentos, políticos, juristas, expertos y ciudadanos, peticiones de reformas constitucionales.

Evidentemente, las motivaciones de cada uno de estos colectivos pueden tener puntos comunes, pero también lógicamente, intereses más específicos dependiendo del colectivo que se trate.

En consecuencia, las peticiones de reforma se dirigen a objetivos diferentes en función del colectivo y del momento y situación política en que se realicen.

Está claro que, en los cuarenta años de existencia de nuestra Constitución, las reformas de esta han sido muy escasas, al menos en el aspecto formal, aunque han sido más numerosas las "mutaciones" que ya mencionaba en la introducción. Durante este mismo periodo lo que si se ha producido en España han sido una serie de cambios importantes a nivel social, económico, territorial y sobre todo político, lo cual hace que parezca un contrasentido que no se hayan acompasado los cambios en nuestro país con los del texto constitucional que rige el funcionamiento de este.

Debemos tener en cuenta, que el 15 de junio de 1977, con la celebración de las primeras elecciones generales democráticas en más de 40 años, puesto que las inmediatamente anteriores se celebraron en febrero de 1936, dio comienzo el proceso democrático de cambio tras la dictadura franquista. ${ }^{16}$ Durante ese periodo, los derechos y las libertades estuvieron seriamente restringidos, los partidos políticos y sindicatos prohibidos, las publicaciones

\footnotetext{
${ }^{16}$ En esas elecciones triunfó el Frente Popular, coalición formada por los partidos de la izquierda (Izquierda Republicana, PSOE, PCE, Partido Obrero de Unificación Marxista y Esquerra Republicana de Cataluña) siendo nombrado presidente de la República Manuel Azaña.
} 
de prensa sometidas a una férrea censura y España como país, aislada en los principales organismos internacionales.

Por lo tanto, al menos hasta los acontecimientos del mayo de París en 1968, que tuvieron una importante repercusión, principalmente en la universidad, con el apoyo de las organizaciones obreras y los partidos políticos ilegales el ejercicio político de los ciudadanos era prácticamente inexistente, y aquellas organizaciones que se atrevían a desafiar las leyes del régimen duramente reprimidas.

Para lograrlo, fue preciso que todos los integrantes de las fuerzas políticas y del Estado entendieran la necesidad de lograr un elevado nivel de consenso y negociación en sus demandas con el fin de dar cabida al resto de aspiraciones.

Para Javier Cercas, el paso de la dictadura a la democracia, no se trató de un pacto de olvido según el cliché historiográfico más común, por el que los vencidos renunciaban a ajustar cuentas a los vencedores por los años de guerra y dictadura, y los vencedores aceptaban un cambio político que acogiese a unos y a otros, idéntico en lo esencial al sistema derrotado en la guerra. Se trató más bien de un pacto de recuerdo por el que de ninguna manera querían repetir los años vividos. (Cercas, 2009: 108-109) ${ }^{17}$

No obstante, podemos considerar que el proceso de elaboración del texto constitucional fue claramente exitoso y puede presumir de grandes luces, pero también adolece de algunas sombras.

Entre las primeras, destaca la forma de hacer el cambio de régimen "de la Ley a la Ley" mediante la aprobación de la Ley para la Reforma Política.

Igualmente, importante, fue la participación de todas las fuerzas políticas, incluso aquellas que estuvieron proscritas durante la dictadura.

Los objetivos marcados en aquel momento se cumplieron. Sin embargo, era muy difícil prever el desarrollo del nuevo modelo de Estado constitucional y la evolución social y sobre todo política del Estado Español, por lo cual, durante el periodo de vigencia de nuestra Constitución se han detectado algunas carencias que ahora se visualizan y que sería preciso corregir.

${ }^{17}$ El autor se basa en los Artículos "Echar al olvido. Memoria y amnistía en la transición” y "El franquismo, historia y memoria de la transición" de Santos Juliá en Claves de la Razón Práctica $\mathrm{n}^{\circ} 129$ y $\mathrm{n}^{\circ} 159$ respectivamente. 
Como decía al principio de este apartado, los aspectos a modificar difieren en función de los actores que los solicitan.

Los ciudadanos se inclinan mayormente por asegurar cuestiones de índole más social, como las pensiones, la sanidad, la enseñanza, el trabajo o la vivienda y en determinadas autonomías el derecho a decidir.

Los partidos políticos orientan sus intereses en función a su ideología, sus expectativas de gobierno, presentes o futuras, así como sus pactos con otras formaciones. Igualmente es importante para ellos la proximidad de citas electorales.

Posiblemente la opinión más equitativa y objetiva podríamos encontrarla en el colectivo de expertos juristas o académicos.

En diciembre de 2008, en el 30 aniversario de la Constitución, el diario EL PAÍS, también solicitó a un grupo de expertos constitucionalistas su opinión sobre la posible reforma de 18 puntos débiles, que podrían haber quedado superados por la evolución de la sociedad o por la legislación como método para realizar reformas constitucionales sin que aparezcan cómo tales formalmente. ${ }^{18}$

De entre los artículos de la Constitución sobre los que se solicitó la opinión de los expertos, destacan los siguientes:

\section{ART 2. NACIONALIDADES}

La reforma del Estatuto de Cataluña de 2006, aprobada en el Parlamento con los votos del PSOE y CIU, texto que el PP impugnó 114 artículos ante el Tribunal Constitucional, introducía en su preámbulo el concepto de "nación" para definir a Cataluña. La reforma del Estatuto de Andalucía lo definía co-

${ }^{18}$ Diario EL PAÍS, 6 de diciembre de 2008. Los expertos consultados fueron los siguientes catedráticos de Derecho Constitucional: María Luisa Balaguer (Universidad de Málaga), Roberto Blanco Valdés (Universidad de Santiago), Gregorio Cámara (Universidad de Granada), Marc Carrillo (Universidad Pompeu Fabra), José Luis Cascajo (Universidad de Salamanca), Francesc de Carreras (Autónoma de Barcelona), Teresa Freixes (Autónoma de Barcelona), Pedro González-Trevijano (Universidad Rey Juan Carlos), Gerardo RuizRico (Universidad de Jaén), Juan José Solozábal (Autónoma de Madrid) y Antonio Torres (UNED). 
mo "realidad nacional". Dada la ambigüedad del texto constitucional, que sólo define la existencia de "nacionalidades y regiones" sin precisar que es cada una de ellas, se plantea la posible necesidad de reformar este artículo.

Alguno de los expertos consultados, abogan por mantenerlo, opinando incluso la conveniencia de su ambigüedad. ${ }^{19}$ Otros expertos consultados abogan por sustituir el término por "comunidades" que es lo que son todas, ${ }^{20}$ o sustituir el "derecho de autonomía" por "principio de autonomía" equivalente al "principio federal" lo cual "en la práctica ya lo es". ${ }^{21}$

\section{ART. 68 SISTEMA ELECTORAL}

El límite máximo de 400 diputados y, especialmente, la circunscripción provincial son trabas para que determinados partidos necesiten obtener mayor número de votos para obtener un escaño.

Abogan no obstante por mantener el límite de escaños, pero sí creen necesario reformar la circunscripción electoral para obtener resultados más proporcionales, eliminando el Art 68.2, para que sea la Ley electoral la que fije la circunscripción, proponiendo varias en las provincias más grandes. ${ }^{22}$ Otros apuntan por mantenerla, pero introduciendo un factor de aprovechamiento de restos en la Ley d'Hondt, ${ }^{23}$ proponiéndose incluso fijar estos restos en 50 escaños en una circunscripción nacional única. ${ }^{24}$

\section{ART. 69 REFORMA DEL SENADO}

En la práctica, esta Cámara, es un clon del Congreso, pero sin poder. El consenso en la necesidad de su reforma es absoluto. "Si no hubiera acuerdo

\footnotetext{
${ }^{19}$ Teresa Freixes y María Luisa Balaguer.

${ }^{20}$ Antonio Torres y Roberto Blanco Valdés.

${ }^{21}$ Francesc de Carreras.

${ }^{22}$ Teresa Freixes.

${ }^{23}$ Marc Carrillo.

${ }^{24}$ Roberto Blanco Valdés.
} 
para reformarlo, habría que plantearse suprimirlo. Si se quitara, todo funcionaría más o menos igual ${ }^{, 25}$

"Es evidente que la circunscripción electoral para el Senado debe ser la comunidad autónoma ${ }^{\prime 26}$ Otras de las modificaciones se referirían a acentuar su "sentido federalizante" 27 , revisar su "función legislativa" para tender a una "mayor paridad o simetría con el Congreso"28. "Mientras no se le atribuya la primera palabra en las materias autonómicas será dificil poder convertir al Senado en la Cámara de representación territorial". ${ }^{29}$

\section{ART.137 LAS COMUNIDADES AUTÓNOMAS (EL MODELO DE ESTADO)}

El Título VIII del texto constitucional, del cual el Art. 137 es el primero, se ha considerado siempre como un texto ambiguo, lo cual no significa que la redacción que se le dio en el momento de elaborar la Constitución no fuera la más adecuada a la situación en que se realizó.

Los expertos consultados coinciden en que, puesto que el derecho a la autonomía ya se ha ejercido en su totalidad por todas las posibles Comunidades Autónomas, habría que dejar reflejada en la Constitución, los nombres de estas y dar por cerrado el modelo.

Para los expertos, se plantean dos debates, uno de ellos sobre Navarra y la conveniencia o no de mantener la disposición referida a la misma, acerca de su posible incorporación a la Comunidad Autónoma Vasca. ${ }^{30}$

Para alguno de los expertos debería conservarse ${ }^{31}$ pero otros abogan por dar por definitivamente cerrado el modelo "[...] impidiendo proyectos inviables politicamente como el de la unión de Navarra al País Vasco". ${ }^{32}$

\footnotetext{
${ }^{25}$ Roberto Blanco Valdés.

${ }^{26}$ Antonio Torres.

${ }^{27}$ Teresa Freixes.

${ }^{28}$ Marc Carrillo..

${ }^{29}$ Pedro González-Trevijano.

${ }^{30}$ Disposición Transitoria Cuarta C.E.

${ }^{31}$ Marc Carrillo.

${ }^{32}$ Antonio Torres.
} 
El otro debate es el orden en el que deben enumerarse las comunidades; por orden de acceso a la autonomía ${ }^{33}$ o alfabético, "[...] porque cualquier otro sería esgrimido como argumento para exigir privilegios". ${ }^{34}$

\section{ARTS. 148 Y 149 Y 150. EL REPARTO DE COMPETENCIAS}

La doble lista de competencias es un aspecto peculiar en la Constitución española que, a juicio de los expertos, exige terminar de definir el modelo.

La opinión mayoritaria es que: "la gran reforma pendiente es ser capaces de cerrar el modelo territorial del Estado [...] Ningún Estado puede soportar, por muy descentralizado que sea, que las comunidades autónomas estén siempre abiertas a la asunción de nuevas competencias. Y eso sólo se puede hacer desde una reforma de la Constitución que, de manera definitiva, defina las competencias de las Comunidades y las propias del Estado que no son susceptibles de delegación". ${ }^{35}$

Para ello, algunos abogan por delimitar de nuevo las competencias. ${ }^{36}$ Otros, por dejar claras las competencias del Estado y nada más. Las competencias del Estado serían las que enumera el art. 149.1, y el resto serian competencias autonómicas, sin más.

Así, los conflictos de competencias serían dirimidos jurisdiccionalmente: "el conflicto, de haberlo, sería jurisdiccional, no de juego político cada vez que hubiera que reformar un estatuto". Y el Art. 150 debería ser derogado "por superfluo". ${ }^{37}$

Sería así mismo necesario, que el texto constitucional aclarara qué es la "legislación básica" y que "la Constitución Española saliese de la ambigüedad". ${ }^{38}$

\footnotetext{
${ }^{33}$ Antonio Torres .

${ }^{34}$ Roberto Blanco Valdés.

${ }^{35}$ Pedro González-Trevijano.

${ }^{36}$ Pedro González-Trevijano y Teresa Freixes.

${ }^{37}$ Francesc de Carreras.

${ }^{38}$ Marc Carrillo.
} 
En consecuencia, basándome en las sugerencias y recomendaciones de estos últimos, considero que las reformas más necesarias serían las referidas a los siguientes aspectos:

- La reforma del Senado y de la Ley Electoral.

- La definición clara de competencias del Estado y las Comunidades Autónomas.

— Una aproximación a la "europeización" de la Constitución.

— El encaje de las "nacionalidades".

Excepto, quizá, el aspecto del punto tercero, el resto de las reformas apuntadas, están bastante interrelacionadas, puesto que todas ellas tienen que ver con la forma de descentralización del Estado escogida en el momento de redactar la Constitución, por lo tanto, no se entendería que se acometiera una de ellas sin que se vieran afectadas las otras dos.

\section{LA REFORMA DEL SENADO Y LA LEY ELECTORAL}

En el Diario de Sesiones del Congreso quedaba registrada la opinión del profesor Tierno Galván acerca de las funciones del Senado tal y como estaba configurado. "Ha quedado una pieza sumamente ambigua, imprecisa, en la que no se sabe bien qué es lo que se está representando, ni para qué va a servir en el fondo, puesto que no es una Cámara de clase, ni parece tampoco que sea exclusivamente una Cámara territorial". ${ }^{39}$

Ciertamente en nuestra Constitución, pese a la definición de ser la "Cámara de representación territorial" ${ }^{40}$ Sus competencias son bastante inferiores a las de la Cámara Baja y además la función atribuida a esta por el texto constitucional no se viene ejerciendo como tal, quedando reducida esta representatividad a la forma de elección de sus componen-

\footnotetext{
${ }^{39}$ Diario de Sesiones del Congreso de los Diputados, núm. 144; 18 de julio de 1978; Pág. 4.364.

${ }^{40}$ Constitución Española Art. 69.
} 
tes y como promotor de algunas iniciativas legislativas, pero siempre con el carácter decisorio final del Congreso de los Diputados.

La función más significativa del Senado es la de autorizar la aplicación del Art. 155 en caso de ser necesaria, como en el momento actual, debiendo ser aprobada por mayoría absoluta del mismo.

A mi juicio, el Senado debería cumplir la función que el texto constitucional le atribuye, pero para ello, debería empezar por cambiarse la forma de la elección de los miembros del mismo, modificando la circunscripción electoral de la provincia a la Comunidad Autónoma. De esta manera, empezaría a representar su función establecida como Cámara de Representación Territorial, o si se prefiere de Representación Autonómica.

Evidentemente, sus funciones actuales, enfocadas a ser un acompañante "de segunda" del Congreso de los Diputados en cuestiones legislativas, podría empezar a asumir funciones de Senado Autonómico, en el cual se debatirían y aprobarían en su caso las leyes, en función de las competencias, de cada Comunidad Autónoma, así como las funciones de interlocutor en las negociaciones con el Gobierno Central.

Para esta última función, habría que calibrar si esas conversaciones serían bilaterales o multilaterales. En todo caso, los planteamientos aprobados por cada Senado Autonómico podrían ser defendidas y debatidas en un órgano, que ya existe, aunque su utilización ha sido, por desgracia, más bien escasa desde su creación, que es la Conferencia de Presidentes de la Comunidades Autónomas.

Este órgano, del máximo nivel político de cooperación entre el Estado y las Comunidades Autónomas, creado en 2004, como un ámbito de actuación abierto y cuya finalidad principal era el debate y la discusión de asuntos de especial relevancia para el sistema autonómico, y por tanto herramienta fundamental de la cooperación teniendo como fin un objetivo cooperativo real, no ha tenido según se puede comprobar demasiado recorrido en la consecución de sus fines. Tiene naturaleza vertical, pues está formada por el presidente del Gobierno y los de las Comunidades y ciudades autónomas y las decisiones son consensuadas.

En concreto, este órgano de cooperación sólo ha sido convocado desde su creación en 4 ocasiones, además de la primera reunión institucional para su creación en 2004. 
En esa primera reunión, el 28 de octubre de 2004, además de institucionalizar la misma, se trató el desarrollo de la participación de las CC.AA. en los asuntos comunitarios europeos y se analizó la financiación en materia de asistencia sanitaria.

El 10 de septiembre de 2005, se acordó la aportación del Estado para la asistencia sanitaria de los años 2006 (3.042,4 millones de euros) y 2007 (3.142,4 millones de euros).

El 11 de enero de 2007 se adopta un acuerdo conjunto sobre Investigación, Desarrollo Tecnológico e Innovación $(\mathrm{I}+\mathrm{D}+\mathrm{i})$, un acuerdo para la creación de Conferencias Sectoriales del Agua y la Inmigración y la Creación de un Grupo de Trabajo para la Elaboración de un Reglamento de la Conferencia de Presidentes.

La cuarta Conferencia tiene lugar el 14 de diciembre de 2009, y en ella se aprueba el Reglamento Interno de la misma, cuya elaboración se acordó en la reunión anterior, se realiza una Declaración sobre la Presidencia Española del Consejo de la Unión Europea para 2010, apoyando las prioridades definidas para la Presidencia, otra sobre Violencia de Género y la necesidad de impulsar los instrumentos para luchar contra ella, y se lleva a cabo un Debate General sobre Empleo, Economía sostenible, Agricultura, Ganadería, Pesca y Política Hidráulica.

La última, por el momento, se produce el 2 de octubre de 2012 y en ella se trató sobre la Estabilidad Fiscal, Situación Económica y laboral de España. ${ }^{41}$

En noviembre de 2014, pocos días antes de la celebración del primer consejo de Política Federal del PSOE en Zaragoza, en el cual se debatirían las propuestas de reforma de la Constitución defendidas por los socialistas, Pedro Sánchez instó al presidente Rajoy la conveniencia de realizar una convocatoria de la Conferencia de Presidentes, tras la consulta independentista en Cataluña, que el líder del PSOE calificó como "el mayor desafío que ha sufrido España".

\footnotetext{
${ }^{41}$ Información obtenida a través de la página web del Ministerio de Hacienda y Administraciones públicas:

http://www.seap.minhap.gob.es/es/areas/politica_autonomica/coop_autonomica/Confer_Pre sidentes.html; 9 de junio de 2015.
} 
No parecen grandes logros para un mecanismo cooperativo, lo cual parece indicar que no existe demasiado interés por parte de los actores de potenciar el mismo, cuando curiosamente si se ha producido una importante competitividad entre Comunidades Autónomas durante su periodo de existencia en la consecución de mayores competencias, que podría haberse sustanciado de forma cooperativa.

Éste instrumento es utilizado en algunos Estados federales europeos, como Alemania, Suiza y Austria.

De acuerdo con el estudio de política comparada del catedrático Blanco Valdés el resultado práctico de este órgano de cooperación en España, ha dado un resultado muy limitado, entre otros motivos por la escasa transcendencia y repercusión de sus acuerdos o conclusiones, así como por el hecho de que, en varias de las reuniones convocadas, no han llegado a asistir la totalidad de presidentes autonómicos. (Blanco Valdés, 2012: 281)

La reforma de la Ley Orgánica del Régimen Electoral General sería necesaria para aplicar los cambios citados más arriba, además de para "facilitar la gobernabilidad del país y evitar la constante presión de las minorías nacionalistas sobre los partidos mayoritarios de ámbito estatal cuando, por su victoria electoral, son titulares del Gobierno de la Nación sin haber alcanzado una mayoría absoluta en el Congreso de los Diputados." 42

Este último objetivo pasaría por una reforma que ajustara la proporcionalidad entre votos y escaños. Un ejemplo claro de esta necesidad lo encontramos en las últimas elecciones de la Comunidad Autónoma de Cataluña, en los cuales, los partidos nacionalistas con 149.081 votos menos que los partidos constitucionalistas, obtuvieron 5 escaños más que estos últimos. ${ }^{43}$

\footnotetext{
42 Arias-Salgado, Rafael; ¿Reforma electoral o reforma Constitucional?; Cuadernos de Pensamiento Político; FAES; Octubre-diciembre 2010; Pag. 109.

${ }^{43}$ Información obtenida de: http://www.juntaelectoralcentral.es/cs/jec/documentos/CATALU\%C3\%91A_2017_Resulta dos.pdf.
} 


\section{LA CUESTIÓN COMPETENCIAL Y EL FIN DEL BIPARTIDISMO}

Uno de los aspectos que quedó bastante falto de definición en el momento de la ponencia del texto constituyente, fue el del reparto de competencias.

El reparto de competencias, dentro del proceso de descentralización llevado a cabo durante la Transición española, no es en definitiva otra cosa que una distribución del poder, político fundamentalmente, aplicada al mencionado proceso de descentralización.

Los estados de corte federalista, como es el caso de España, no tendrían sentido alguno si en los mismos los órganos políticos de los respectivos entes territoriales, llámense estados federados o comunidades autónomas no pudieran ejercer un poder propio, materializado en el ejercicio de facultades y competencias de diversos tipos. (Blanco Valdés, 2012: 194)

El caso español tiene determinadas singularidades que lo hacen especifico, pero, sin embargo, en sus aspectos principales, sería indiferente la forma en que se gestó, es decir, bien partiendo de una adhesión de territorios soberanos, como en el caso estadounidense o como en el español de una descentralización territorial.

En consecuencia, la estructura de poderes en los estados federales se articula en dos tipos de poderes, son los poderes repartidos, es decir la división de facultades y competencias entre el gobierno federal y los estados federados, y los poderes compartidos tendentes fundamentalmente a la cooperación entre ambos.

Este ejercicio de distribución del poder representa por lo tanto unos de los logros fundamentales de los sistemas democráticos, adopten estos una u otra forma de Estado, para el mantenimiento de la convivencia.

Una vez decidido e iniciado el proceso descentralizador, con el objetivo de propiciar el auto gobierno de los entes "federados" que constituyen las distintas Comunidades, se inició lo que, parafraseando a Blanco Valdés, podríamos denominar la carrera de las liebres y las tortugas, con el objetivo principal por parte de ambos colectivos, de obtener en el menor tiempo posible, el mayor grado de "poder" en sus respectivos territorios, enmarcado éste en la capacidad de tomar decisiones en el ámbito legislativo y económico principalmente. 
Está claro que éste era el objetivo de la ponencia constitucional, pero la incertidumbre sobre el futuro y las circunstancias en que se desarrollaría este proyecto exigía la toma en consideración de una serie de precauciones, para llevarlo adelante de forma controlada, que quizá lo encorsetó excesivamente.

Este aspecto, es uno de los de mayor importancia dentro del proceso de descentralización, dado que la necesidad de mantener un exquisito equilibrio de poderes entre el Estado Central (o Federal) y las Comunidades Autónomas o Estados Federados es vital, por una lado para no restringir las libertades de las Comunidades, y por otro para no vaciar de competencias al Estado, que en última instancia, es además el garante del equilibrio de los derechos de todos y cada uno de los Estados que lo componen.

De esa manera, para situarnos en el contexto del problema, es conveniente tener en cuenta el desarrollo de este desde los orígenes.

Estaba claro que un Estado de estas características no tendría razón de ser, si simplemente se demarcaban territorios y no se les dotaba de materias sobre las que asumir competencias para desarrollar la autonomía de que se pretendía dotarles.

De igual modo, estaba claro que el Estado como tal debía mantener una serie de materias exclusivas, no transferibles, en sectores de actividad que afectaban a la totalidad de este y debían ser ejercidas en términos de igualdad y de forma coordinada, sin dejar posibilidad a fisuras por razones de interés o conveniencia de las distintas entidades que formaban el Estado Autonómico.

A tal efecto, la Constitución desarrolla dentro del Título VIII, quizá el más "provisional" de todos los del texto constitucional, dos listas de materias para distribuir las competencias en sus Arts. 148.1 y 149.1 respectivamente.

El primero relaciona las materias sobre las cuales las competencias podrían ser asumidas, de forma inmediata, por las Comunidades Autónomas y el segundo, aquellas materias de competencia exclusiva del Estado. Hay que señalar, que en estas materias, la competencia del Estado es en unos casos exclusiva, en otros sobre las bases y en otras sobre la legislación.

No obstante, el Art. 148.2 abre la puerta a la ampliación de competencias por parte de las Comunidades Autónomas, transcurridos cinco años y mediante la reforma de sus Estatutos, para ampliar sus competencias dentro del marco del Art. 149. 
Así, el Art. 149.3, intenta zanjar la cuestión de las materias no delimitadas expresamente como de competencia estatal mediante una cláusula de cierre, para zanjar la indeterminación del texto constitucional, por la cual, las materias no relacionadas en el Art. 149.1 como competencia exclusiva del Estado, podrán ser asumidas por las Comunidades Autónomas en virtud de sus respectivos Estatutos, al tiempo que adjudica la competencia de las materias no asumidas por las Comunidades Autónomas en sus Estatutos, al Estado, el cual ejercerá el Derecho supletorio en lo no legislado por las Comunidades.

Siguiendo a Blanco Valdés, en su magnífico estudio de política comparada, "Los rostros del federalismo" este artículo, está estructurado en cuatro principios.

Los dos primeros, definen una doble cláusula residual de atribución de competencias: las materias no atribuidas al Estado podrán ser asumidas por las Comunidades en sus Estatutos, y las competencias no asumidas por estas, corresponderán al Estado. El tercer principio, de prevalencia, establece la superioridad de las normas del Estado en caso de conflicto con las Comunidades, en todo lo que no sea competencia exclusiva de aquellas, y el cuarto de supletoriedad que dispone que el derecho estatal será supletorio del de las Comunidades. (Blanco Valdés, 2012: 214)

Un tercer artículo, el 150, regula en sus 3 apartados la coordinación de competencias legislativas. "Las Cortes Generales, en materia de competencia estatal, podrán atribuir a todas o a alguna de las Comunidades Autónomas la facultad de dictar, para sí mismas, normas legislativas en el marco de los principios, bases y directrices fijados por una ley estatal." Estableciéndose en cada ley marco la modalidad de control de dichas Cortes sobre las normas de las Comunidades.

Mediante Ley Orgánica, el Estado podrá transferir o delegar facultades correspondientes a materias de titularidad estatal, susceptibles de ello, previendo la transferencia de medios financieros y formas de control del Estado. Finalmente, el Estado podrá en aras del interés general, y por mayoría absoluta de cada Cámara, dictar leyes que armonicen disposiciones normativas de las Comunidades Autónomas, en materias atribuidas a la competencia de estas. 
El sistema de doble lista rige sólo para Canadá y el Estado español. El autor mencionado anteriormente, llega a la conclusión de que "... en realidad, quien fija las competencias autonómicas en España no es la Constitución sino los respectivos Estatutos para todas y cada una de sus Comunidades, de modo que la determinación del grado de autogobierno regional no queda fijado en la Constitución, sino en manos de las normas estatutarias, que pueden alterarlo de forma permanente." (Blanco Valdés, 2012: 214)

Como se puede apreciar, esta ordenación de materias y competencias, en apariencia perfectamente organizada, tenía no obstante varios atajos, que fueron debidamente aprovechados por los entes Autonómicos para ampliar competencias de la forma más rápida posible, incluso en materias reservadas exclusivamente al Estado.

Igualmente, la disposición transitoria segunda de la Constitución, establece que "Los territorios que en el pasado hubiesen plebiscitado afirmativamente proyectos de Estatuto de Autonomía y cuenten, al tiempo de promulgarse esta Constitución, con regímenes provisionales de autonomía, podrán proceder inmediatamente en la forma que se prevé en el apartado 2 del artículo 148, cuando así lo acordaren, por mayoría absoluta, sus órganos preautonómicos colegiados superiores, comunicándolo al Gobierno." A esta disposición, se acogieron el País Vasco y Cataluña, lo que las convertía de alguna manera en Comunidades de "primera", en detrimento del resto de Comunidades.

Todos estos aspectos, produjeron un mimetismo emulador entre Comunidades, ya que ninguna quería evidentemente quedar al margen de las ampliaciones competenciales conseguidas por otras, lo cual generó no pocos agravios comparativos, que muchas veces terminaron con la presentación de recursos de inconstitucionalidad y deterioro del consenso entre fuerzas políticas, en momentos en que dicho consenso resultaba imprescindible.

Los resultados más visibles fueron nuevamente, que a través de pactos puntuales o de legislatura, encaminados a facilitar la gobernabilidad o la acción legislativa de gobiernos sin mayorías absolutas, las Comunidades Autonómicas, fueron adquiriendo fundamentalmente competencias en materias diversas y especialmente en recursos de financiación, en la medida en que fuera necesaria la colaboración de partidos nacionalistas o 
regionalistas en las instituciones del Gobierno central o de los Parlamentos autonómicos.

Este proceso, se debe también en gran medida a la aparición de nuevos partidos políticos, que acabaron con el bipartidismo de la primera época de la transición democrática. Este fenómeno generó una importante desestabilización del sistema, a merced del cual se aprovecharon circunstancias de índole político.

Esto no significa que no sea positiva la pluralidad de partidos. Evidentemente en democracia esta pluralidad es un derecho prioritario, sin embargo, utilizada para conseguir beneficios — que no necesariamente tienen porque ser espurios- en detrimento de la igualdad con otras Comunidades, si pueden introducir en el sistema factores que lo hagan menos igualitario y de carácter competitivo, en busca de la obtención de mayores competencias que el resto de los entes autonómicos.

Esto, supone una disfunción del sistema político, ya que puede suponer duplicidad de funciones, que generen un incremento presupuestario, que a su vez puede implicar mayor presión fiscal y al mismo tiempo una importante disminución del gasto social - otro de los derechos fundamentales de nuestro Estado de Derecho - que si puede afectar de forma más directa al Estado de Bienestar.

Naturalmente, la evolución de los diferentes Estados federales ha dependido en gran medida también de las circunstancias particulares de los mismos, sus orígenes históricos, sus conflictos civiles internos o exteriores, la progresiva ampliación o reducción de su extensión territorial (caso por ejemplo de la URSS, en la cual la caída del régimen comunista dio origen a la Federación Rusa) y las crisis económicas.

Esto lleva según el autor citado a que cada Estado federal haya tenido una evolución singular, pero no obstante es posible realizar paralelamente una generalización, concretada en la identificación de dos modelos federales, de naturaleza opuesta en muchos ámbitos, denominados federalismo dual y federalismo cooperativo. El primero de ellos va a ir evolucionando poco a poco hacia el segundo, que es el que actualmente prevalecería en la mayoría de los estados federales. (Blanco Valdés, 2012: 239 y ss.)

Como ya hemos mencionado, el caso español es un caso singular, en tan- 
to en cuanto tiene como origen un proceso constituyente no orientado al federalismo, pues fue un proceso de descentralización administrativa, en el cual no se regula explícitamente en su texto constitucional el modelo de Estado descentralizado, al que finalmente evolucionó el Estado de las Autonomías.

Sin embargo, la ambigüedad o provisionalidad en los artículos referidos a las competencias, Arts. 148, 149 y 150, en los que sólo prevé específicamente la concurrencia del Estado central y las Autonomías en materia cultural, la realidad es que una buena parte de las competencias exclusivas del Art. 149.1 han acabado por configurarse como compartidas, con lo que ello implica en materia de coordinación legislativa y cooperación política y administrativa. A esto debemos unir la facultad de las Comunidades Autónomas en la coordinación de competencias legislativas y la potestad de transferencia del Estado a las mismas de materias de titularidad estatal susceptibles de transferencia o delegación de acuerdo con el Art. 150.2 y la facultad del Estado para armonizar las disposiciones normativas de las Comunidades bajo ciertas condiciones del Art. 150.3.

Todo esto implica la existencia de un Estado federal cooperativo, no explicitado quizá de forma fehaciente, pero sí de facto, que quizá por éste motivo, adolece según mi parecer de defectos que lo hacen en ocasiones susceptible de una utilización más de índole negociadora, a cambio por ejemplo de apoyos parlamentarios, que de índole realmente cooperativa entre el Estado y las Comunidades y entre éstas últimas entre sí, en una especie de competición para obtener el mayor número de competencias, acentuándose así las diferencias entre Comunidades.

En este fenómeno, influye también de forma muy intensa el incremento del número de partidos políticos en el escenario español, que ha finiquitado el bipartidismo vigente en las primeras legislaturas de la restauración democrática.

Estos hechos, parecen confirmar la teoría expuesta anteriormente de la carrera de las liebres y las tortugas, por lo que podemos llegar, por una parte, a la conclusión de que en España el federalismo cooperativo tendría aún mucho camino por recorrer, cuando debería ser una meta ya alcanzada después de casi cuatro décadas de estado de las autonomías, y por otra a la de 
que las Comunidades autónomas, y muchas veces también el gobierno central prefieren la bilateralidad en sus relaciones, lo cual es propicio a la generación de diferencias entre las mismas.

Según un estudio realizado por varios profesores de Derecho Constitucional y Administrativo, "Para superar este modelo podría plantearse la constitucionalización del reparto sobre la técnica federal clásica que fija en la Constitución las competencias que corresponden al Estado (Federación) y deja las restantes a las Comunidades Autónomas (Estados, Länder), sin perjuicio de algunas cláusulas generales, como la prevalencia, que reduzcan la conflictividad actual (art. 148, 149 y 150 CE). Una mayor concreción constitucional del reparto garantiza su estabilidad y, por ende, la seguridad jurídica."

"En cualquier caso, si más allá de la inconcreción se quiere abordar el problema de la excesiva conflictividad competencial habria que garantizar la participación de las Comunidades en la determinación de las regulaciones básicas del Estado a desarrollar por aquéllas. Si los territorios participan de forma vinculante en la concreción de esos elementos comunes, el acuerdo con el Estado sobre su contenido es necesario y, por tanto, la conflictividad se reducirá." 44

\section{LA EUROPEIZACIÓN DE LA CONSTITUCIÓN}

Los Artículos del 93 al 96 del texto constitucional se refieren a los Tratados Internacionales, estableciendo las condiciones y los requisitos para la adhesión a los mismos.

Como mencionaba en la introducción al presente artículo, nuestra Constitución ha sufrido lo que el profesor Tajadura, denomina cambios no formales o mutaciones constitucionales. La adhesión a Tratados como el de Maastricht, Lisboa o Niza, además del Tratado de Estabilidad Presupuestaria,

\footnotetext{
44 Santiago Muñoz Machado, Eliseo Aja Fernández, Ana Carmona Contreras, Francesc de Carreras Serra, Enric Fossas Espadaler, Víctor Ferreres Coma, Javier García Roca, Alberto López Basaguren, José Antonio Montilla Martos, Joaquín Tornos Mas; Ideas para una reforma de la Constitución; Madrid 20 de noviembre de 2017.
} 
aunque no han modificado el texto constitucional, si han cambiado el significado de alguna de sus disposiciones.

A pesar de que este aspecto no es el problema más candente dentro de los asuntos a reformar, si parece un contrasentido, en tanto en cuanto, una vez que somos miembros de pleno derecho de la Unión Europea, no deberíamos tener problema alguno para reconocerlo explícitamente, puesto que esta pertenencia, además de voluntaria y claramente beneficiosa para nuestro país, nos ha obligado, y nos obligará a la realización de más mutaciones constitucionales, dado que el carácter de la Unión Europea, como Organismo Político vivo y con necesidades de adaptación a las modificaciones que como tal precise así lo exigirá.

Es evidente, por lo tanto, que la europeización del texto Constitucional es una de las tareas que habrá que asumir más temprano que tarde, puesto que la pertenencia a Organismos Internacionales implica la aceptación de determinadas normas, pue pueden entrar en colisión con nuestros textos legales. Especialmente la integración en la Unión Europea va a suponer la necesidad de nuevas modificaciones, por lo tanto, obviar esta necesidad es una especie de "ceguera voluntaria" que podría solucionarse con bastante facilidad, puesto que un proceso de reforma de los artículos que se refieren a los Tratados Internacionales se podría modificar por el procedimiento ordinario.

En nuestro texto constituyente se especifica que se podrá mediante Ley Orgánica autorizar los tratados por los cuales se atribuya a una organización o institución internacional el ejercicio de competencias derivadas de la Constitución, correspondiendo a las Cortes Generales o al Gobierno la garantía del cumplimiento de estos. Art.93 CE.

La prestación del consentimiento del Estado para obligarse por medio de tratados o convenios requerirá la previa autorización de las Cortes Generales, en los siguientes casos:

a) Tratados de carácter político.

b) Tratados o convenios de carácter militar.

c) Tratados o convenios que afecten a la integridad territorial del Estado o a los derechos y deberes fundamentales establecidos en el Título I. 
d) Tratados o convenios que impliquen obligaciones financieras para la Hacienda Pública.

e) Tratados o convenios que supongan modificación o derogación de alguna ley o exijan medidas legislativas para su ejecución. Art.94 CE.

Por último, si el tratado contiene estipulaciones contrarias a la Constitución se exigirá la previa revisión constitucional, pudiendo ser requerida por el Gobierno o las Cortes al Tribunal Constitucional la constatación de si existe o no esa contradicción. Art.95 CE.

Como se puede observar, se trata de normas generalistas, cosa natural, ya que en el momento de redactarse el texto constitucional España aún no pertenecía a muchos organismos internacionales.

Nuestra pertenencia a la Unión Europea nos obliga a lo que podríamos considerar como "cesiones de soberanía", que emanan de las Instituciones de esta, como el Parlamento Europeo, el Tribunal de Justicia de la Unión Europea o el Banco Central Europeo. En consecuencia, su institucionalización dentro del texto constituyente sería perfectamente lógica.

\section{EL ENCAJE DE LAS NACIONALIDADES}

"Los problemas que plantea el título VIII solo pueden ser resueltos por el poder de reforma. Su intervención es necesaria para reemplazar una normativa constitucional pensada para crear un Estado Autonómico, por otra cuya finalidad sea regular su correcto funcionamiento.

En todo caso, cualquier reforma debe partir del reconocimiento expreso de su finalidad y sus límites. Y nunca podría ser legítimamente utilizada para poner en cuestión los fundamentos del Estado, su unidad y la igualdad de todos los ciudadanos." 45

El Título VIII de la Constitución regula la Organización Territorial del Estado, especificando claramente los tipos de Entidades que la forman, locales, provinciales y autonómicos y sus derechos. Como ya hemos visto en el

${ }^{45}$ Tajadura Tejada, Javier; "Reforma, mutación y destrucción de la Constitución"; Fundación FAES; Cuadernos de Pensamiento Político nº 58 ABRIL/JUNIO 2018; Pág. 13. 
apartado dedicado a la cuestión competencial, entre las diversas Comunidades Autónomas ha existido desde el principio de su organización un sentimiento emulador entre las mismas por la obtención de competencias.

Sin embargo, en algunas de ellas, además de la ambición competencial, han surgido también movimientos nacionalistas, cuyo objetivo declarado, más o menos explícitamente es el de la independencia del resto del territorio nacional.

Especialmente significativos han sido estos movimientos en la Comunidad Autónoma Vasca, y en Cataluña, donde continuamente ha habido presiones y actuaciones encaminadas a lograr este objetivo.

En esta última, se llegó a declarar formalmente la independencia aprobada por el Parlamento Catalán en 27 de octubre del 2017, tras la celebración de un referéndum ilegal el 1 de octubre del mismo año y el compromiso asumido por Puigdemont el día 10 del mismo mes, en base a los resultados del mencionado referéndum, de que Cataluña se convirtiera en una república independiente, aunque inmediatamente solicitó la suspensión de los efectos de dicha declaración para iniciar un proceso de dialogo.

Estos hechos motivaron la intervención de la Autonomía Catalana a través del Art. 155 de la Constitución, hasta la celebración de nuevas elecciones y la constitución de un nuevo gobierno.

A la vista de estos acontecimientos, es evidente, la existencia de inquietudes en lo que respecta al encaje de las nacionalidades en la Constitución.

Sin embargo, la reforma necesaria para realizar el encaje territorial y de los nacionalismos exigiría un nuevo proceso constituyente, en el cual no sería posible conceder lo que estos, especialmente el nacionalismo catalán, aspiran a conseguir que no es otra cosa que la independencia. Esto sería imposible, puesto que el principio de unidad territorial sería un límite infranqueable para el poder de revisión.

En ese sentido, se han manifestado los tribunales constitucionales de Italia, Alemania, y el Tribunal Supremo estadounidense. En todos los casos han establecido el carácter indestructible de la unidad territorial.

En nuestra Constitución, el Art. 168 prevé la posibilidad de una revisión total del texto constituyente, lógicamente con todas las garantías y requisitos del procedimiento agravado, y el Tribunal Constitucional lo ha interpretado 
como la facultad de reforma total, dando así la posibilidad de la destrucción del texto constituyente y la apertura de uno nuevo con un proceso de reformas que cambie los pilares básicos de la unidad territorial.

Desde determinados partidos políticos, se aboga por una reforma federalizante de la Constitución. En concreto el secretario general del PSOE Pedro Sánchez, trasladó al Grupo Socialista en el Congreso de los Diputados la orden de impulsar ya la Comisión Territorial para abordar la reforma de la Constitución.

El objetivo del secretario general era que estuviera en funcionamiento antes de final de año, pero, y a pesar de quedar constituida a finales de noviembre, la primera reunión del nuevo organismo de la Cámara Baja no tuvo lugar hasta la semana pasada, con la presencia de los padres de la Constitución, José Pedro Pérez Llorca, Miguel Herrero de Miñón y Miquel Roca.

La invitación de los tres constitucionalistas, y sobre todo su posterior intervención en la Comisión, han levantado ampollas en el Grupo Socialista, donde se empieza a dar por amortizada, al menos en lo que queda de legislatura, la iniciativa de reformar la Constitución. ${ }^{46}$

Es cierto que nuestra Constitución no define el modelo de Estado como federal, sino que en su Título VIII lo define como organizado territorialmente en municipios, provincias y en las Comunidades Autónomas que se constituyan, a continuación, define claramente que todas estas entidades gozan de autonomía para la gestión de sus respectivos intereses. ${ }^{47}$

Tras esta declaración de intenciones, absolutamente clara y transparente, se establecen, entre otras cosas, los modos de acceso a la Autonomía, teniendo en cuenta hechos diferenciales que ya se han expuesto en capítulos anteriores, mediante los cuales las distintas regiones pueden alcanzar sus aspiraciones legítimas de autogobierno y gestión.

El desarrollo del Estado de las Autonomías durante los casi cuarenta años de vigencia del texto constitucional demuestra claramente que esta declaración de intenciones no quedaba en una mera formalidad, y durante los mis-

\footnotetext{
${ }^{46}$ Información obtenida de:

https:/www.elconfidencialdigital.com/politica/Nuevo-traspie-Pedro-Sanchez-

constitucional_0_3077692215.html del 18 de enero de 2018

${ }^{47}$ Constitución Española Art. 137.
} 
mos, las diferentes autonomías han alcanzado un elevado nivel de autogestión política e institucional.

El desarrollo del Estado de las Autonomías durante los más de treinta y cinco años de vigencia del texto constitucional demuestra claramente que esta declaración de intenciones no quedaba en una mera formalidad, y durante los mismos, las diferentes autonomías han alcanzado un elevado nivel de autogestión política e institucional.

Por lo tanto, no es demasiado comprensible desde un punto de vista objetivo, el debate sobre la necesidad de reformar el texto constitucional a fin de que figure en el mismo la definición de Federal, ya que, "[...] dificilmente puede caminarse hacía donde ya se está” (Blanco Valdés, 2005: 80).

Es bien cierto, como ya se ha mencionado en el presente artículo, que la construcción del modelo de Estado Español constituye lo que, en palabras del mismo autor, sería un federalismo construido del revés en el que la unidad no se alcanza desde una desunión territorial previa, como en el caso de los Estados federales más genuinos, como los Estados Unidos, Canadá o Argentina, sino a través de un proceso de desaparición de la centralización mantenida durante decenios por la fuerza. (Blanco Valdés, 2005: 83)

Conviene tener en cuenta, que la definición exacta de Estado federal es muy compleja, y más que un conjunto de características rígidas para conceptualizarlo, puede constituirse sobre diferentes articulaciones de las relaciones entre los ciudadanos y sus gobiernos e instituciones, sin que haya paralelismos absolutos.

Por lo tanto, a mi entender una reforma en el sentido de denominar a España como un estado federal, no sólo no tendría sentido, sino que podría potenciar nuevos impulsos secesionistas. La solución a los problemas de este tipo que se dan en la actualidad debería encauzarse a través del diálogo entre las Comunidades y el Gobierno Central, partiendo de las premisas de respeto a la Ley y a la Constitución.

No obstante, en el momento actual tras la crisis provocada por el independentismo, en su afán por obtener por cualquier medio la secesión y el inmovilismo, tanto del Gobierno Central como de los partidos independentistas, y el resultado de las últimas elecciones generales y las inconsistencias de los responsables autonómicos a la hora de formar gobierno, a lo que ca- 
bría añadir, que una vez formado este es muy probable que sigan manteniendo posiciones independentistas, la solución a este problema no se ve muy cercana, puesto que las actitudes y declaraciones del nuevo Presidente, antes y después de su nombramiento, indican su intención de persistir en un proceso que camine hacia la independencia.

\section{BIBLIOGRAFÍA}

Barrera, Carlos 2004. "La transición democrática (1975-1978)", en Javier Paredes Coord. Historia contemporánea de España Siglo XX, Madrid: Editorial Ariel.

Blanco Valdés, Roberto 2005, "Nacionalidades Históricas y Regiones sin Historia”, Madrid: Alianza Editorial.

Blanco Valdés, Roberto 2012. "Los rostros del federalismo", Madrid: Alianza Editorial.

Cercas, Javier 2009. "Anatomía de un instante”, Barcelona: Random House Mondadori, S.A., Sexta edición en Debolsillo 2012.

http://www.juntaelectoralcentral.es/cs/jec/documentos/CATALU\%C3\% 91A_2017_Resultados.pdf 